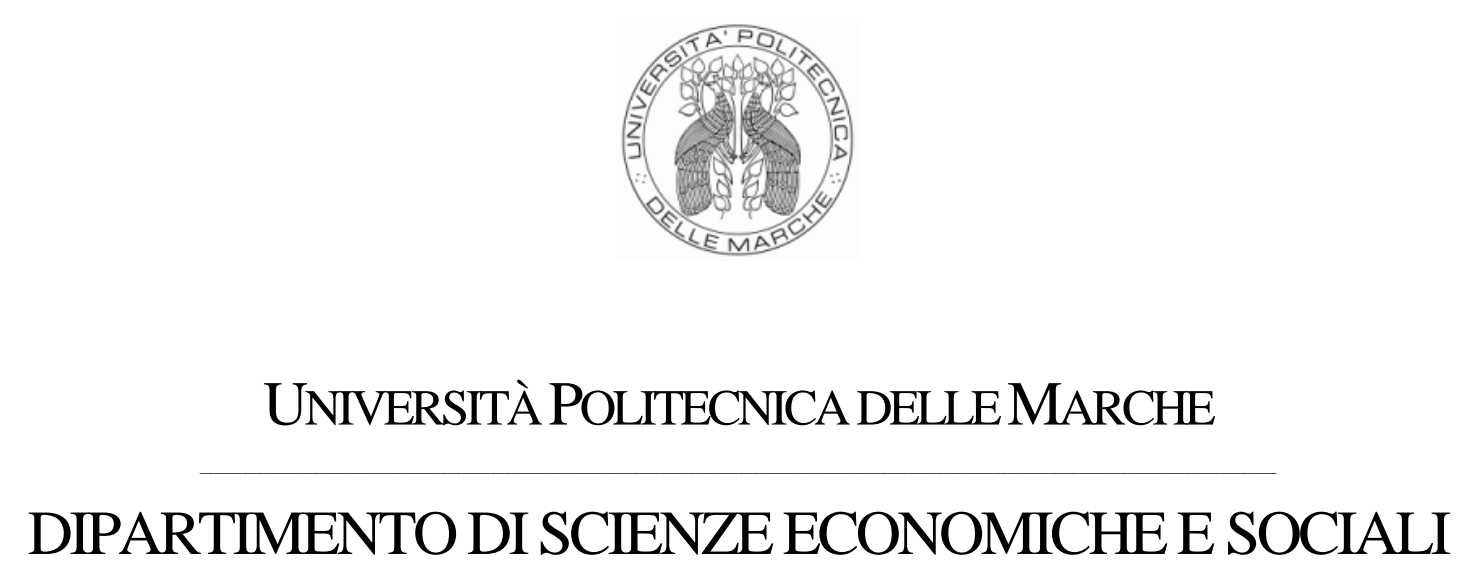

WILL UGLY BETTY EVER FIND A JOB IN ITALY?

GIOVANNI BUSETTA \& FABIO FIORILLO

QUADERNO DI RICERCA n. 391

ISSN : 2279-9575

Ottobre 2013 
Comitato scientifico:

Renato Balducci

Marco Gallegati

Alberto Niccoli

Alberto Zazzaro

Collana curata da:

Massimo Tamberi 


\title{
Will Ugly Betty ever find a job in Italy?*
}

\author{
Giovanni Busetta $^{* *}$ and Fabio Fiorillo*** \\ preliminary version, do not quote
}

JEL classification: C93, J71, J78

Keywords: beauty premium, racial discrimination, experimental economics.

\begin{abstract}
This paper evaluates the impact of beauty on employability, stressing the first stage of the hiring process. In particular, we studied the Italian labor market in order to ascertain whether there exists a preference for attractive applicants according to gender and racial characteristics. The sample analyzed consists of observations collected by sending 11008 curricula vitae (henceforth CVs) to firms looking for workers in response to advertised job postings.

Positive responses were obtained by $3278 \mathrm{CVs}$ (almost $30 \%$ of the sample). We then compared response rates of different categories, obtaining the following results: those who receive the highest levels of positive responses are attractive subjects; most of the responses to plain subjects involve unqualified jobs; beauty appears to be essential for front clerical work; racial discrimination appears to be significant, but less so than discrimination based on physical features, especially for women.
\end{abstract}

\section{Introduction}

In 2006, ABC started a new TV series called "Ugly Betty", which ironically explores the impact of concepts such as beauty, class, race, and sex. This series won several awards because it represents a possible way to shed the light on this kind of discrimination in everyday life. Betty Suarez is an unattractive 22-year-old Mexican American. She lands a job at Mode, a trendy, high fashion magazine in Manhattan. The series thereby examines all the possible discrimination concerning gender, attractiveness, and race in the labor market. The success of the series reflects the attention paid by those in the USA to discrimination issues.

Could Ugly Betty find a job in Italy? Is discrimination based on attractiveness a major problem for the Italian labor market? What kind of discrimination most characterizes the hiring process in Italy?

\footnotetext{
* The authors wish to thank Annalisa Busetta, Stefano Staffolani, Massimo Tamberi, and Alberto Zazzaro for their advices.

${ }^{* * *}$ Corresponding author: Department of Economics, Business, Environmental Sciences and Quantitative Methods Via

T. Cannizzaro 278, 98122 Messina, Italy.

*** Department of Economics, Università Politecnica delle Marche, Piazzale Martelli 8, 60121 Ancona, Italy.
} 
The ranking of Italy in the gender gap index is reported by Hausman, Tyson, and Sahidi (2012). This index is equal to $100 \%$ if there is no discrimination and it decreases with discrimination. With a score of $67 \%$ Italy lies outside the top 50 non-discriminatory countries. It ranks 80th, alongside Honduras, Greece, and Ghana, far behind the Philippines (6th, 78\%), Germany (13th, 76\%), Cuba (19th, 74\%), and Spain (26th, 73\%). Therefore, at least at gender level, discrimination problems would appear to exist.

According to Arrow (1971), motivations of discrimination could be analyzed from an economic perspective. When a firm discriminates in the hiring process, a positive (negative) value is basically assigned to certain characteristics (gender, race, beauty...), even if these characteristics are not directly linked to employee productivity. Discrimination based on beauty and gender results if a firm's manager believes that an unattractive woman could depress the productivity of male staff, in which case the lack of beauty is a cost (a negative externality) and discriminatory behavior is a way to internalize it. If this belief is true, the firm's behavior is rational. In the discrimination context, it matter little whether this belief is true or false, but what does matter is that such behavior is at odds with the UN's Declaration of Human Rights (1944). The only discrimination that may be admitted for different hiring behavior is a true difference in individual productivity among workers.

In this paper, we do not directly inquire into motivations for discriminatory behavior in Italy. Rather, we wish to investigate the profile of discrimination, and examine whether gender distinctions characterizing the latter half of the 20th century and due to cultural characteristics (lower level of women's education and their preference not to participate in the labor force) continue to hold, or whether growing immigration and the change in cultural models (so-called "Berlusconismo" or "Velinismo"; see Hipkins 2011) could produce specific discrimination patterns.

Our study analyzed all job postings displayed in the period between August 2011 and September 2012. Producing resumes based on the European format and structure and using fictitious names and addresses, we sent $11008 \mathrm{CV}$ s to 1542 advertised job openings receiving on average a callback rate of almost $30 \%$. In order to analyze the impact of gender, race and attractiveness, we sent the same resumes with the same skills several times to all companies, changing the photo attached or attaching no photo. The methodology was a binary probit, a nonlinear model, used to inquire into the influence of discrimination based on several features on the probability of a candidate being called to a job interview.

The rest of the paper is organized as follows. Section 2 reviews the literature concerning the impact of gender, race and attractiveness on an individual's employability in the labor market. In Section 3, the data used in the empirical analysis are described as well as the methodology applied. In Section 4 we present the main empirical results and Section 5 concludes.

\section{Related literature}

Individuals attribute a broad range of positive traits to physically attractive people. This is one of 
the main conclusions emerging from decades of beauty research in psychology. One of the papers published on this topic analyzed the impact of attractiveness on career prospects (Dion et al., 1972). The authors established that physically attractive people are perceived to be more sensitive, kind, modest and outgoing.

Following this pioneering paper, Feingold (1992) demonstrated a robust association for both men and women between physical attractiveness and numerous personality traits (social skills, mental health and intelligence). His main idea in this respect is that companies prefer attractive rather than an unattractive people because attractive people are considered more competent. Moreover, Hamermesh (2011) recently discussed the advantages of beautiful people in labor, loans and marriage markets, in sales and in happiness.

Several laboratory experiments have investigated the role of beauty in the labor market. In particular, Heilman and Saruwatari (1979) found that while attractiveness is advantageous for men, both in managerial and clerical positions, it is advantageous for women only for clerical jobs and disadvantageous for managerial positions. Cann, Siegfried and Pearce (1981) found that men and attractive candidates continue to be significantly preferred over women and their non-attractive counterparts, even after evaluating specific skills.

Biddle and Hamermesh (1994) reached the same conclusions after studying data from the US and Canada. Their main findings were as follows: attractiveness plays an important role in deciding employees' earnings; the penalty for not being attractive is greater for women than men, and it is robust across occupations. In a study on graduates from a prestigious law school (Biddle and Hamermesh, 1998), the same authors found that a weakly positive and insignificant relationship between attractiveness and earnings for lawyers becomes higher and significant as working years accrue.

More recently, Mobius and Rosenblat (2006) performed an experimental game in which employers paid wages to workers according to their ability to perform a maze-solving task. Even if physically attractive workers are no better than less attractive ones, they are offered higher wages. Parrett (2007) showed that attractive waitresses receive higher tips compared to non-attractive ones, while the same does not happen for waiters. As the author administered a questionnaire on the quality of service provided by the server to his sample of consumers, he could control for server productivity. In this way, he concluded that pure customer discrimination based on beauty is the only reason underlying the observed beauty premium for female waitresses.

Another crucial aspect influencing job opportunities concerns discrimination based on the race of the applicant. Conventional labor force and household surveys collect data which cannot be easily used to measure racial discrimination or to analyze its mechanics. This is because they do not contain all the characteristics that employers observe when hiring, promoting or setting wages. The difficulty in using conventional data has led to the use of either pseudo-experiments or audit studies. The first strand of the literature, such as Goldin and Rouse (2000), examines the effect of blind auditioning on the hiring process, measuring the amount of discrimination. The second strand, known as audit studies, provides data on comparable minority and white subjects in actual social 
and economic settings. In this way, how each group is approached by potential employers in such settings is measured. The weakness of this kind of study lies in three main aspects. First of all, both members of the auditor pair has to be identical in all their characteristics, except for race. Even if attempts are made to match auditors on several characteristics and train them for several days, these two devices are not always able to eliminate all of the differences between auditors (Heckman and Siegelman 1992, and Heckman 1998). Secondly, such studies are not double-blind: as auditors know the purpose of the study, they could behave in such a way as to influence data either in favor or against the existence of racial discrimination (Turner et al. 1991). Finally, audit studies are extremely expensive, which makes it difficult to generate large enough samples to avoid significant differences in outcomes across pairs.

Most analyses of the two issues (influence of beauty and race on the hiring process) consist of small samples of student subjects answering hypothetical questions on hiring decisions. By contrast, our analysis was based on a much larger sample of real job openings posted by actual employers. The underlying idea was thereby to evaluate the potential existence of a preference for attractive candidates. Moreover, we investigate whether this preference interacts with the applicant's sex and whether it depends on a number of observable job characteristics. Finally, we compare the impact of attractiveness and racial components in order to evaluate which of the two appears to be more relevant to the issue in hand.

Moreover, most of the papers on this topic focus on beauty and racial discrimination with respect to differential salaries. On the contrary, the paper we present focuses on job-search discrimination based on attractiveness and race. One criticism leveled at most of the empirical studies on this topic concerns the impossibility for researchers to control for employee qualifications and skills. By contrast, the design of our experiment gives us complete control and observability over candidate backgrounds: our applicants are identical in every respect (including their education, work experience, language and computer skills) for each kind of job offer, changing only name, nationality, sex, race and pictures (or lack thereof) in their CVs. Moreover, the applications completely fulfill employer requirements regarding education, experience and so on.

The papers closest to the present analysis in terms of experimental design are those of Bertrand and Mullainathan (2004), Rooth (2009), Ruffle and Shtudiner (2010), and Boò, Rossi and Urzua (2013). While Bertrand and Mullainathan (2004) and Rooth (2009) sent fictitious CVs in response to advertised job openings to investigate respectively racial and obesity discrimination, Ruffle and Shtudiner (2010), and Boò, Rossi and Urzua (2013) used the same methodology to investigate the impact of attractiveness.

The first of the above-mentioned papers studied racial discrimination, based on a dataset constructed by sending 2435 fictitious CVs. In order to investigate racial discrimination, the authors used different names distinctly associated with Whites and African Americans. Using this method, large racial differences were found in callback rates. Applicants with White names needed to send about $10 \mathrm{CVs}$ to get one callback, whereas those with African American names had to send around 15 resumes to get one callback. This 50 percent gap in callback rates is statistically significant. Based on their estimates, a White name yields as many more callbacks as an additional eight years 
of experience and, since applicants' names are randomly assigned, this gap can only be attributed to name manipulation.

Rooth (2009) manipulated CV photos digitally in order to have both normal-weight and obese applicants. The results of this analysis show that both men and women received significantly lower callback rates in the event of obesity.

Also Ruffle and Shtudiner (2010) responded to job advertisements. In particular, the two authors sent 5312 CVs to 2656 advertised job openings in Israel. CVs of women with no picture have a significantly higher callback rate than those of attractive or plain-looking women. The authors explained this finding as being connected to female jealousy of attractive women and a negative perception of women (but not men) who include pictures of themselves on their CVs.

Bóo, Rossi, and Urzua (2013) performed an empirical strategy based on the same experimental approach. They sent fictitious resumes with pictures of attractive and unattractive faces to real job openings in Buenos Aires, Argentina. The results of the experiment suggest that attractive candidates should attach a photograph to their resumes when given the opportunity to do so, since including a photograph increases the probability that they will be called for interview by about 30 percent. Unattractive candidates, on the other hand, should not attach a photograph to their resumes: this reduces the probability of receiving a callback by about 5 percent.

Concerning Italian labor market a previous analysis (Busetta, Fiorillo and Visalli, 2013) using the same dataset of the present paper demonstrates that in order to classify callback rates the best ordering is the one based on attractiveness.

To our knowledge, the only other study dealing with the impact of beauty in Italy is Ponzo and Scoppa (2012). The two authors studied, in particular, the impact of Professors' beauty on teaching evaluation finding strong evidence of its influence.

\section{Data and methodology}

The sample analyzed consists of observations collected by sending $11008 \mathrm{CV}$ s to firms looking for employees in response to 1542 advertised job postings. All of the CVs were sent in the period between September 2011 and August 2012. During this period, we regularly scrutinized job postings on all the main online job service websites offering positions in Italy, namely lavoratorio.it, Lavoro\&Stage, Miojob, Lavorare.net, Page Personnel, Trovalavoro, Kijiji, Inique Agenzia, Archimede agenzia per il lavoro, Manpower divisione Horeca, Combinazioni s.r.l, Quanta agenzia per il lavoro, Humangest, Alma, Orienta agenzia per il lavoro, Varese centro per l'impiego, Adecco, Obiettivo lavoro, Temporary agenzia per il lavoro, Free work, Maw, Euro Interim, Mr Comunication, and Open Job. In order to prevent firms detecting that the CVs in question were fake, all the websites that we analyzed were those which required no registration. 
The same ${ }^{1} \mathrm{CV}$ was sent to firms eight times: four CVs with different photos of applicants and four without photos. The CVs with photos were sent attaching each time the photo of attractive and unattractive Italian women, and attractive and unattractive Italian men. A CV containing no photo of an Italian and an African (in terms of name and origin) was sent to each firm for both genders. In all, $9680 \mathrm{CVs}$ for both male and female vacancies were sent to 1210 firms. Applications from female (male) workers were invited by 127 (205) firms, and 508 (820) CVs were sent to them, each firm receiving only four CVs per vacancy.

Table 1 - Summary Statistics

\begin{tabular}{|c|c|c|c|c|}
\hline & & & CVs sent & Call back rate \\
\hline \multirow{6}{*}{$\begin{array}{l}\text { Candidate } \\
\text { characteristics }\end{array}$} & \multirow[t]{4}{*}{ Picture } & Attractive Italian & $25 \%$ & $50 \%$ \\
\hline & & Italian with no photo & $25 \%$ & $39 \%$ \\
\hline & & Unattractive Italian & $25 \%$ & $17 \%$ \\
\hline & & Foreigner with no photo & $25 \%$ & $13 \%$ \\
\hline & \multirow[t]{2}{*}{ Gender } & Men & $51 \%$ & $32 \%$ \\
\hline & & Women & $49 \%$ & $28 \%$ \\
\hline \multirow[t]{15}{*}{ Job characteristics } & \multirow[t]{2}{*}{ Public / Office } & Front office & $41 \%$ & $28 \%$ \\
\hline & & Back office & $59 \%$ & $31 \%$ \\
\hline & \multirow[t]{2}{*}{ Strength } & Hard work & $16 \%$ & $42 \%$ \\
\hline & & Soft work & $84 \%$ & $27 \%$ \\
\hline & \multirow{3}{*}{$\begin{array}{l}\text { Qualification } \\
\text { required }\end{array}$} & No qualification & $32 \%$ & $38 \%$ \\
\hline & & High school & $43 \%$ & $28 \%$ \\
\hline & & Graduated & $25 \%$ & $23 \%$ \\
\hline & \multirow{8}{*}{$\begin{array}{l}\text { Function } \\
\text { offered }\end{array}$} & Managers & $5 \%$ & $32 \%$ \\
\hline & & Professionals & $8 \%$ & $26 \%$ \\
\hline & & Technicians & $37 \%$ & $27 \%$ \\
\hline & & Clerical jobs & $14 \%$ & $32 \%$ \\
\hline & & Sales workers & $15 \%$ & $16 \%$ \\
\hline & & Service workers & $5 \%$ & $41 \%$ \\
\hline & & $\begin{array}{l}\text { Skilled and craft workers, } \\
\text { machine and plant operators }\end{array}$ & $9 \%$ & $35 \%$ \\
\hline & & Elementary occupation & $6 \%$ & $43 \%$ \\
\hline
\end{tabular}

As regards the pictures to include in the CVs, we selected photographs from the Internet and

\footnotetext{
${ }^{1}$ As a precautionary measure, in order not to let employers realize that they were receiving identical CVs, we staggered the dispatch of the CVs to the same firms over a few days. For the same reason, we used different names and addresses. All the addresses belonged to the city of Rome in order not to make the scrutinizers perceive the candidates as different because of where they lived. Finally, we randomly chose the order of CVs sent to the same firm.
} 
modified them in order to make them unrecognizable. We then asked 100 students at the University of Messina to choose which of the people in the photos they considered to be attractive and unattractive. As almost all of them (92\%) agreed on the classification, we are confident that subjectivity can be excluded from the choice. We created a Gmail account for each of the candidate categories, including this email address on the $\mathrm{CV}$ as contact information.

Table 1 summarizes the characteristics of job openings in our dataset. The abbreviations in brackets are those that will be used in the analysis below. The sample was equally divided into CVs which included photos of an attractive (A) and an unattractive (U) person, and CVs including no photo of an Italian and a foreigner (F). The number of CVs for men (M) was slightly higher than for women (W) because there are more job postings looking only for men than those requiring only women.

The data collected with this method gave us the opportunity to explore the effect of a picture and its attractiveness (or lack thereof) on the likelihood of being invited for a job interview. Moreover, sending CVs with no photos allowed us to consider as a benchmark the Italian individuals with no information on their attractiveness and to control for racial discrimination. Finally, our design strategy of sending fake CVs which exactly meet the firms' requirements allowed us to eliminate matching problems as a possible explanation for the difference in the rate of response.

Being aware that beauty might be relevant and contribute to worker productivity in some of the fields involved in the advertised job postings, we decided to divide job positions into front- and back-office tasks. Indeed, we classified all job openings according to whether the position involves face-to-face (Fr) contact with the public. In particular, we classified as front office jobs those which either explicitly stated that the job required face-to-face contact with people, or where such contact could be unequivocally inferred from the job advertisement. Otherwise, the job is classified as back office. We then included in the first category, for instance, jobs belonging to fields like sales and customer service. By contrast, we decided to include in the back-office category jobs like accounts management, budgeting, industrial engineering, and computer programming.

While $40.52 \%$ of the job openings in our sample are positions that involve face-to-face contact (Fr), the remaining $59.48 \%$ are job positions which do not require any kind of contact in person with the customer. Another distinction that we made was between jobs for which physical strength is required (16.39\% of our observations), and jobs for which it is not required $(83.61 \%$ of our observations). As for front and back office jobs, we classified as hard work either jobs for which physical strength is explicitly required, or those for which it may be unequivocally inferred. Otherwise, they are classified as jobs which do not imply hard work.

The last characteristics that we considered in the analysis are the qualifications required and the functions offered. As regards the former, $32.09 \%$ of our sample of job offers required no qualification, $42.95 \%$ required a high school diploma $(\mathrm{Hi})$, and $24.96 \%$ a university degree $(\mathrm{G})$. In terms of functions offered, managers accounted for $4.94 \%$ of job offers, professionals posts for $8.07 \%$, technical jobs $37.39 \%$, clerical jobs $13.59 \%$, commercial posts $20.53 \%$, skilled workers $7.99 \%$, drivers $1.31 \%$ and elementary occupation $6.18 \%$ (Based on International Standard Classification of Occupations - ISCO). 
In Table 1 the distribution of call back rates is presented. In respect to attractiveness, it emerges that attractive Italian people have much higher call back rates $(50 \%)$ than unattractive ones (17\%) and Italians with no photo (39\%). Also racial discrimination appears to be significant. Furthermore, markedly lower callback rates are associated to foreign candidates (13\%). According to gender classification, men get $32 \%$ of callbacks, while women $28 \%$.

Regarding front and back office classification, we obtained $31 \%$ for those entailing back office work and $28 \%$ for those involving front office work. With respect to hard and "soft" jobs, $42 \%$ is the callback rate for jobs involving hard work, and $27 \%$ for those not entailing hard work.

In terms of qualifications required, we obtained the highest callback rates for jobs which do not require any qualification (38\%), while jobs for graduate candidates obtained $28 \%$ and jobs for high school diploma candidates obtained $23 \%$ (Table 1).

In terms of the ISCO classification of jobs, we have $43 \%$ for elementary occupations, $41 \%$ for wire workers, $35 \%$ for craftsmen and workers, and definitely lower callback rates for managers (16\%), and scientific and intellectual professions (26\%).

As some of the job offers concern either only women or only men, we divided the observations into gender categories. Table 3 shows the differences between women and men in terms of different types of jobs and the relevant education required.

Table 2 - Distribution of job postings by gender

\begin{tabular}{|c|c|c|c|c|c|c|c|c|c|c|}
\hline & $\begin{array}{c}\text { Front } \\
\text { office }\end{array}$ & $\begin{array}{c}\text { Back } \\
\text { office }\end{array}$ & Tot. & $\begin{array}{c}\text { Non- } \\
\text { hard } \\
\text { work }\end{array}$ & $\begin{array}{c}\text { Hard } \\
\text { work }\end{array}$ & $\begin{array}{c}\text { Tot. } \\
\text { qualifica } \\
\text { tion }\end{array}$ & $\begin{array}{c}\text { High } \\
\text { school }\end{array}$ & Grad. & Tot. \\
\hline Women & $21.26 \%$ & $78.74 \%$ & $100 \%$ & $93.82 \%$ & $6.18 \%$ & $100 \%$ & $64.79 \%$ & $22.75 \%$ & $12.46 \%$ & $100 \%$ \\
\hline Men & $19.26 \%$ & $80.74 \%$ & $100 \%$ & $89.79 \%$ & $10.21 \%$ & $100 \%$ & $67.30 \%$ & $20.20 \%$ & $12.50 \%$ & $100 \%$ \\
\hline
\end{tabular}

It is important to point out that the percentage of hard work postings for women is lower than that for men. This may also explain the gender differences for No qualification and High school job postings. In effect, Hard work is highly correlated with No qualification. 


\section{Table 3 - Relation between job characteristics and classification}

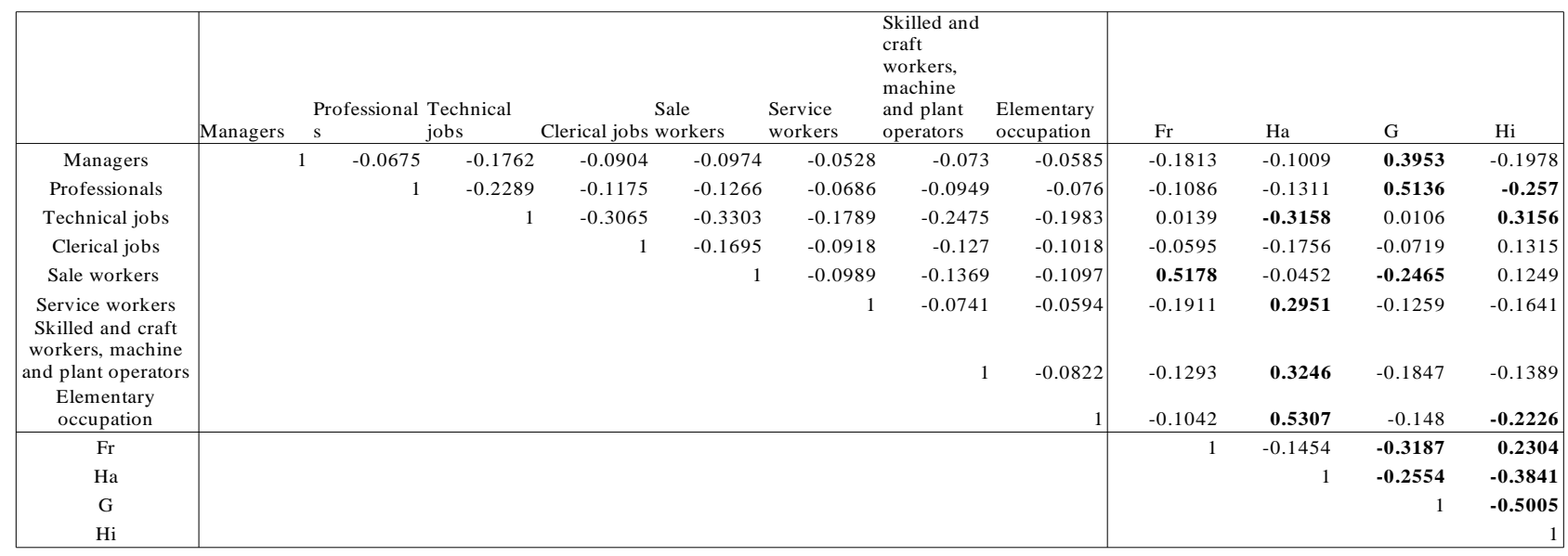

The correlation between job characteristics and classification is shown in Table 3 The matrix shows that, while graduate jobs are strongly positively correlated to executive and specialized jobs, they are negatively correlated to sales, front office and hard work. On the other hand, high school jobs are strongly positively correlated to technical and front office jobs and negatively correlated to unskilled and hard work. Obviously, vacancies requiring high school qualifications are strongly negatively correlated to those requiring university degrees. Front office jobs are highly positively correlated to sales staff, and finally hard work is strongly positively correlated to service work, workmen and to unskilled work and negatively correlated to technical jobs.

As our goal was to obtain as many responses as possible from employers (our dependent measure), we included in the CVs all the characteristics required by the advertised job postings. Moreover, we did not add to the CVs any more than the qualifications required so that the applicants would not be perceived as over-qualified. As we sent identical CVs within each advertised job posting, differences in response rates between candidates can only be due to different pictures or lack thereof.

Throughout the analysis that we present below, our dependent variable is whether the employer emails back the applicant for an interview. In particular, the response variable (from now on RISP) is equal to 1 if the employer emailed the applicant to invite him/her for an interview and 0 if no such email was initiated. Other variables included in all the analyses as regressors are regional dummies and job classification. While the former is a dummy variable which takes the value of 1 if the job vacancy comes from a certain Italian region and 0 otherwise, the latter is a dummy variable concerning job classification, and takes the value of 1 if the job considered belongs to a certain sector and 0 otherwise.

We estimate both non-genderified probit models and corresponding genderified models. In each model the constant refers to a normal individual applying for a firm located in Lazio for a technical job from whom the firm requires no other characteristic. Other parameters measure the difference in respect to such an individual. 
In each model we estimate the probability of receiving an email with the invitation for an interview

$$
\mathrm{P}(\mathrm{RISP}=1)=\mathrm{P}(\mathrm{x} \leq z)=\int_{-\infty}^{z} f(x) d z
$$

where $x$ is normally distributed with density $f(x)$ and cumulative distribution $F(z)$, and $\mathrm{z}$ is:

$$
z=\gamma_{0}+\sum_{r} \gamma_{r} d_{r}+\sum_{l} \gamma_{l} d_{l}+\Gamma \alpha+\beta_{A} A+\beta_{U} U+\beta_{F} F+\Phi \phi
$$

where $\left(d_{r}\right)$ are regional dummies (reference Lazio), while $\left(d_{l}\right)$ are job classification dummies (reference technical job). $\Gamma$ is a matrix of job characteristic dummies (education level, front office, hard work) and $\alpha$ are the related parameters. Parameters $\beta_{A}, \beta_{U}, \beta_{F}$ measure the difference in $z$ when the applicant is attractive, unattractive or foreign (with no photo) in respect to an Italian applicant sending a $\mathrm{CV}$ with no photo. Obviously $A, U, F$ are dummy variables for the same attributes. $\Phi$ is the interaction matrix between beauty judgment and job characteristics and/or job classification, and $\phi$ are the related parameters.

Then we genderify our model, estimating $z$ as follows:

$$
\begin{aligned}
z & =W\left[\gamma_{w}+\sum_{r} \gamma W_{r} d_{r}+\sum_{l} \gamma W_{l} d_{l}+\Gamma \alpha W+\beta W_{A} A+\beta W_{U} U+\beta W_{F} F+\Phi \phi W\right] \\
& +M\left[\gamma_{w}+\sum_{r} \gamma M_{r} d_{r}+\sum_{l} \gamma M_{l} d_{l}+\Gamma \alpha W+\beta M_{A} A+\beta M_{U} U+\beta M_{F} F+\Phi \phi M\right]
\end{aligned}+
$$

where the generic parameter $\delta W$ is one of the above parameters in equation 2 for women, and $\delta M$ is that for men. We also test a non-genderification null hypothesis ${ }^{2}$ :

$$
\delta W=\delta M
$$

\section{Results}

The analyses that we performed consist of four linear probability models summarized in Table 4 below.

In the first estimation (Model 1) we do not consider any interaction (hence $\Phi=0$ ), unlike in the others. As we show in Table A5 of the Appendix, all the tests (McFadden $R^{2}$, LnL, Schwarz's and Akaike's criteria, correct prediction percentages) indicate that, if we do not consider interactions, we provide a weak model.

\footnotetext{
${ }^{2}$ It is worth pointing out that "genderification" has the same parameters of two separate estimations for women and for men. Hence we can consider the complete variance matrix and to test the null hypothesis of equation 4.
} 
Table 4 - Model specification

\begin{tabular}{|c|c|c|c|c|}
\hline & Model 1 & Model 2 & Model 3 & Model 4 \\
\hline $\begin{array}{l}\text { Regional dummies } \\
\left(d_{r}\right)\end{array}$ & YES & YES & YES & YES \\
\hline $\begin{array}{l}\text { ISCO class. } \\
\text { Dummies }\left(d_{l}\right)^{\text {. }}\end{array}$ & YES & YES & YES & YES \\
\hline $\begin{array}{l}\text { Attractiveness and } \\
\text { Nationality } \\
(A, U, F)\end{array}$ & YES & YES & YES & YES \\
\hline $\begin{array}{l}\text { Job } \\
\text { Characteristics }(\Gamma)\end{array}$ & YES & YES & NO & YES \\
\hline $\begin{array}{l}\text { Attractiveness and } \\
\text { Nationality } \\
\text { interacted with Job } \\
\text { Characteristic } \\
(A, U, F) * \Gamma \\
\end{array}$ & $\mathrm{NO}$ & YES & NO & YES \\
\hline $\begin{array}{ll}\text { Attractiveness } & \text { and } \\
\text { Nationality } & \\
\text { interacted } & \text { with } \\
\text { ISCO class. } \\
(A, U, F) * d_{l} \\
\end{array}$ & NO & $\mathrm{NO}$ & YES & YES \\
\hline
\end{tabular}

Other models differ in respect to different interaction matrices and the control variables that we use. In Model 2 we interact beauty levels with job characteristics $(\mathrm{Fr}, \mathrm{Ha}, \mathrm{G}, \mathrm{Hi})$, with no consideration of job classification. In Model 3 beauty is interacted with job classification, without considering job characteristics. Since there is a good correlation between job classification and job characteristics in this model, we do not consider job characteristic dummies, but only job classification ones (hence $\Gamma=0$ ). This specification is the only one which presents normal residuals (Table A5). In Model 4, we consider all the variables of the previous models. This model provides the best prediction and performance ${ }^{3}$. The results seem robust since they do not qualitatively change among models.

We leave all the estimates to the Appendix. Here we just recall the main results.

Table A1 of the Appendix shows the parameters which refer to regional dummies $\left(d_{r}\right)$. As we might expect, firms in each region have different callback rates, and most of the times the coefficients associated to regions are statistically significant. Moreover, callback rates differ by gender. In particular, for four regions the probability of being called back is higher for women (Piedmont,

\footnotetext{
${ }^{3}$ Since the ISCO job classification and job characteristics are correlated, the absence of multicollinearity in Model 4 is tested. Test results are available upon request.
} 
Friuli V.G., Marche and Sardinia), for 14 regions it is higher for men (Valle d'Aosta, Lombardy, Trentino Alto Adige, Veneto, Liguria, Emilia Romagna, Tuscany, Umbria, Abruzzo, Molise, Puglia, Basilicata, Calabria, and Sicily), and for the remaining two regions (Lazio and Campania) there is no statistically significant difference. Regional distribution of callbacks does not show therefore any dualism between North and South of Italy in terms of gender discrimination.

In Table A2 of the Appendix we display the direct effect of applying for different job classification and characteristic. The former are indicated by $\left(d_{l}\right)$, and the latter by front office $(\mathrm{F})$, hard work $(\mathrm{Ha})$, and education level (graduate "G" and high school "Hi"). Moreover, we analyze the beauty premium, observing the values of $\beta_{A}, \beta_{U}, \beta_{S}$. If we consider different kinds of jobs, we can easily see that, while "executive" callback rates are significantly lower than those of technical jobs, there are no gender differences between the job classifications. Additionally, clerical callback rates are significantly higher, with a significant gender premium in favor of women. Gender acts in favor of women also for sales staff, with a lower callback rate than that for technical jobs. Finally, we observed a significantly positive higher probability of callback for specialized labor, service workers, workmen and unskilled workers if the applicant is male.

As regards the beauty premium, attractive people seem to have a higher chance of being recontacted by the firm. These results are in line with those obtained by Moyer (2010) in France. In this respect, the author showed a major difference in callback rates to job interview between attractive (42\%) and unattractive $(16 \%)$ candidates during the first stages of the hiring process. Furthermore, the beauty premium seems to be definitely more relevant to women than to men. Moreover, there is a cost of unattractiveness: the callback rate is lower for unattractive people and such a cost is higher for women. Furthermore, foreigners experience a lower callback rate compared to White people but, in this case, women are recontacted more than men.

As regards the direct impact of job characteristics (Models 1, 2 and 4), the findings are not as clearcut as previous ones. While front office and graduate applications experience lower callback rates, higher callback rates are recorded for "hard work" applicants. Gender differences seem to exist in this respect, but they are not statistically significant.

In Table A3 of the Appendix we compared parameters $\phi$ related to the interactions between beauty and job characteristics (only for Model 2 and Model 4). On the one hand, as expected, attractiveness provides a beauty premium for "front work". On the other hand, for graduates and high school leavers, such a premium is higher for women. On the contrary, attractiveness reduces the callback rate for hard work, and such a cost is higher for women. This suggests that women and men have different job opportunities and that such opportunities depend on beauty. Symmetrically, unattractiveness is a cost in terms of job-seeking, and this cost is higher for front office tasks and for women, while it seems to be an advantage for hard work, in particular for men. No statistically conclusive results emerge for foreign candidates.

Finally, in Table A4 of the Appendix, we compare the effects of interaction between beauty and job classifications (only for Models 3 and 4). In both models the results are similar. In particular, with regard to foreigners, female employability seems to be higher than male. Attractiveness gives 
aspiring executives and sales staff an advantage, while it seems to be disadvantageous for specialized jobs, service workers, workmen and unskilled workers. Moreover, employability seems to be higher in executive and specialized job sectors for attractive women than for attractive men. That is to say that, for executives, being good looking seems to be a prerequisite for the job.

Table 5 - Probability distribution of callback rates

\begin{tabular}{|c|c|c|c|c|c|}
\hline & benchmark & $\mathrm{A}$ & $\mathrm{U}$ & $\mathrm{S}$ & \\
\hline WOMAN & $39 \%$ & $40 \%$ & $12 \%$ & $14 \%$ & \\
\hline \multirow[t]{2}{*}{ MAN } & $46 \%$ & $49 \%$ & $45 \%$ & $8 \%$ & \\
\hline & & $\mathrm{F}$ & $\mathrm{Ha}$ & $\mathrm{G}$ & $\mathrm{Hi}$ \\
\hline \multirow{2}{*}{\multicolumn{2}{|c|}{$\begin{array}{r}\text { WOMAN } \\
\text { MAN }\end{array}$}} & $34 \%$ & $54 \%$ & $27 \%$ & $38 \%$ \\
\hline & & $37 \%$ & $52 \%$ & $37 \%$ & $41 \%$ \\
\hline & & F_A & Ha_A & G_A & Hi_A \\
\hline \multirow{2}{*}{\multicolumn{2}{|c|}{$\begin{array}{r}\text { WOMAN } \\
\text { MAN }\end{array}$}} & $58 \%$ & $29 \%$ & $38 \%$ & $52 \%$ \\
\hline & & $69 \%$ & $17 \%$ & $36 \%$ & $42 \%$ \\
\hline & & F_U & Ha_U & G_U & Hi_U \\
\hline \multirow{2}{*}{\multicolumn{2}{|c|}{$\begin{array}{r}\text { WOMAN } \\
\text { MAN }\end{array}$}} & $0 \%$ & $1 \overline{4} \%$ & $3 \%$ & $6 \%$ \\
\hline & & $10 \%$ & $65 \%$ & $25 \%$ & $14 \%$ \\
\hline \multirow{3}{*}{\multicolumn{2}{|c|}{$\begin{array}{r}\text { WOMAN } \\
\text { MAN }\end{array}$}} & F_S & Ha_S & G_S & Hi_S \\
\hline & & $1 \overline{2} \%$ & $14 \%$ & $5 \overline{\%}$ & $7 \overline{\%}$ \\
\hline & & $4 \%$ & $22 \%$ & $10 \%$ & $6 \%$ \\
\hline
\end{tabular}

From the estimation of Equation 3 using the Model with the best performance (Model 4) we can calculate the estimated probabilities of receiving a callback (table 5). The probability of receiving a callback for a benchmark individual is $39 \%$ for a woman who sent a CV with no photo, with no particular level of education explicitly required, applying for a back office job or one not entailing hard work. For the corresponding man the estimated callback rate is $46 \%$. Importantly, the impact of attractiveness in a technical job is not so high $(+1.3 \%$ and $+3.5 \%)$, but it is really high for female graduates, where a callback probability of $27 \%$ increases to $38 \%$ if the $\mathrm{CV}$ includes the photo of an attractive woman. On the contrary, if the photo is of an unattractive woman, the callback probability for graduates is reduced by up to $3 \%$. A female foreign graduate has more chance of receiving a callback (about 5\%). It is worth noting that for a man the impact of attractiveness exists but is less pronounced.

Our results are in line with the findings of Bóo, Rossi, and Urzua (2013), who performed an empirical strategy based on a similar experimental approach: They sent fictitious resumes with pictures of attractive and unattractive faces for real job openings in Buenos Aires, Argentina. The results of the experiment suggest that attractive candidates should attach a photograph to their resumes when given the opportunity to do so, since including a photograph increases the probability that they will be called for interview by about 30 percent. Unattractive candidates, on the other hand, should not attach a photograph to their resumes since including a photograph decreases the probability of receiving a callback by about 5 percent. Our evidence is even more striking because the difference between responses to applications with no photo and unattractive applicants is even higher. 
Thus, we can conclude that, generally speaking, when attractiveness is a feature required by job vacancies, women have an advantage over men. However, in this case an unattractive woman is more discriminated against than an unattractive man. Indeed, an unattractive woman has no chance of being called back to interview for an executive task.

\section{Conclusion}

In the present analysis we used a field experiment based on real job on-line openings in Italy to test the existence of either a beauty, gender or/and racial premium at the early stage of job search. The sample analyzed consisted of observations collected by sending $11008 \mathrm{CVs}$ to firms looking for workers in response to advertised job postings. Positive answers were obtained by $3278 \mathrm{CVs}$ and negative answers, where no response was forthcoming, were obtained by $7730 \mathrm{CVs}$.

From the performed analysis connected to attractiveness and nationality of the candidates to a job interview discrimination based on attractiveness seems to be more correlated to gender than to racial discrimination.

Comparing the response rates of different categories, we obtained the following results: attractive subjects are those who receive the highest levels of positive answers; both unattractive and foreign candidates obtained lower callback rates. Attractiveness is quantitatively more important for women than for men: attractive women have higher callback rates than attractive men. That said, an unattractive woman receives fewer offers than an unattractive man. This result is more marked for certain kinds of jobs. Most responses to unattractive subjects involve low-skilled jobs. On the one hand, beauty appears to be essential for front office and executive jobs. On the other, unattractiveness appears to strongly reduce chances not only of interviews for executive and front office jobs, but also for clerical jobs. This effect is more pronounced for women.

Racial discrimination appears to be substantial, but less prominent than discrimination based on physical features, especially for women. In particular, it seems that being an unattractive woman has a higher negative impact than the positive one of being attractive. However, unattractive individuals have a higher probability of receiving a callback if they apply for a hard and poorly qualified job than a "soft" and highly qualified one.

Thus we can conclude that attractiveness is relevant to almost all kinds of jobs and also to those which require high qualifications (managerial and specialized). In these cases, women have an advantage over men. By contrast, unattractive candidates receive a sizable number of callbacks only when they apply for low-skilled jobs which require no contact with people. In other words, it seems that a woman wishing to find a good job in Italy has to be attractive. On the contrary, an unattractive woman, even if she is highly qualified, has little chance of getting a highly-skilled job, at least if she applies on-line and attaches a photo. 


\section{References:}

Arrow, K. (1971), "The theory of discrimination". Princeton University Working Paper 30A.

Busetta, G., Fiorillo F. and Visalli E. (2013), "Searching for a job is a beauty contest", MPRA Paper No. 49825, posted 15. September 2013 17:32 UTC.

Bertrand, M. and Mullainathan S. (2004), "Are Emily and Greg More Employ-able than Lakisha and Jamal? A Field Experiment on Labor Market Discrimination", American Economic Review, 94:4, 991-1013.

Biddle, J.E. and Hamermesh D.S. (1994), "Beauty and the Labor Market", American Economic Review, 84:5, 1174-1194.

Biddle, J.E. and Hamermesh D.S. (1998) 'Beauty, Productivity, and Discrimination: Lawyers' Looks and Lucre", Journal of Labor Economics, 16:1, 172-201.

Bóo, L.F., Rossi, M.A. and Urzua S. (2013), "The Labor Market Return to an Attractive Face: Evidence from a Field Experiment”, Economic Letters, 118 (1), 170-172.

Cann, A., Siegfried W.D. and Pearce L. (1981) "Forced attention to specific applicant qualifications: Impact on physical attractiveness and sex of applicant biases", Personnel Psychology, 34, 65-75.

Dion K., Berscheid E. and Walster E. (1972), "What is beautiful is good", Journal of Personality and Social Psychology, 24, 285-290.

Feingold A. (1992), "Good-Looking People Are Not What We Think", Psychological Bulletin, $111: 2,304-341$.

Goldin, C. and Rouse C. (2000), "Orchestrating Impartiality: The Impact of Blind Auditions on Female Musicians", The American Economic Review, 90 (4): 715-741.

Hamermesh D. (2011) Beauty Pays, Princeton: Princeton University Press.

Hausman R., Tyson L., Sahidi S. (2012) The Global Gender Gap Report. World Economic Forum.

Heckman J.J. (1998), "Detecting Discrimination," The Journal of Economic Perspectives, 12 (2): 101-116.

Heckman J.J. and Siegelman P. (1992), "The Urban Institute Audit Studies: Their Methods and Findings", in Michael Fix and Raymond J. Struyk, Clear and Convincing Evidence: Measurement of Discrimination in America, Lanham, MD: Urban Institute Press.

Heilman, M. E. \& Saruwatari, L. R. (1979) "When beauty is beastly: The effects of appearance and sex on evaluations of job applicants for managerial and non-managerial jobs, Organizational Behavior and Human Performance, 23, 360-372.

Hipkins D. (2011) "Whore-ocracy'. Show Girls, the Beauty Trade-Off, and Mainstream Oppositional Discourse in Contemporary Italy". Italian Studies, 66 (3), 413-430.

Mobius, M.M. and Rosenblat, T.S., (2006) "Why Beauty Matters", American Economic Review, 96:1, 222-235.

Moyer G.H. (2010), " L'hyper place de la beauté dans les critères de sélection en phase de recrutement ", Revue internationale de psychosociologie, à paraître.

Parrett, M., (2007) "Beauty and the Labor Market: Evidence from Restaurant Servers", unpublished manuscript.

Ponzo, M. and Scoppa V., (2013), "Professors' Beauty, Ability, and Teaching Evaluations in Italy", 
The BE Journal of Economic Analysis \& Policy: 1-25, forthcoming.

Rooth, D.O., (2009), "Obesity, Attractiveness, and Differential Treatment in Hiring”, Journal of Human Resources, 44:3, 710-735.

Ruffle, B., and Shtudiner, Z., (2010), “Are Good-looking People More Employable?” Monaster Center for Economic Research and Ben-Gurion University of the Negev, Discussion Paper No. 10-06.

Turner, M.A., Struyk R.J. and Yinger J. (1991), "Housing Discrimination Study Synthesis", Washington DC: Urban Institute Press. 


\section{Appendix}

Table A1: Regional dummies

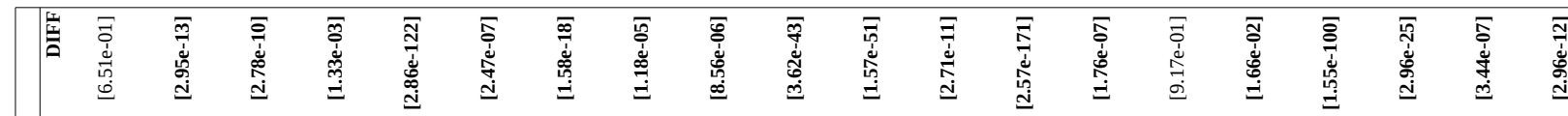

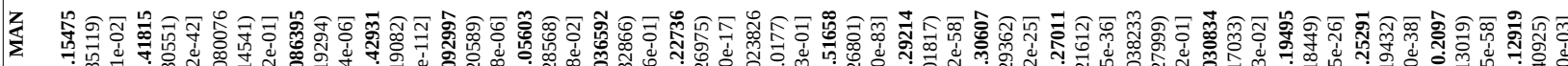

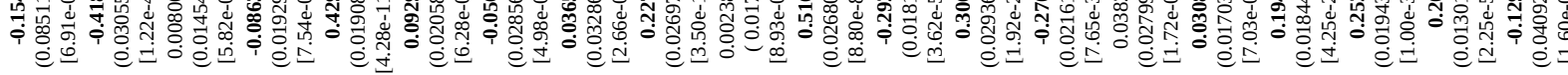

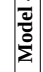

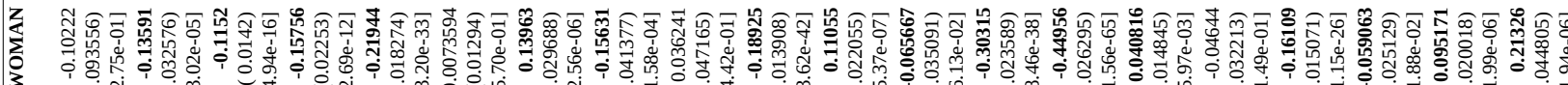

4.

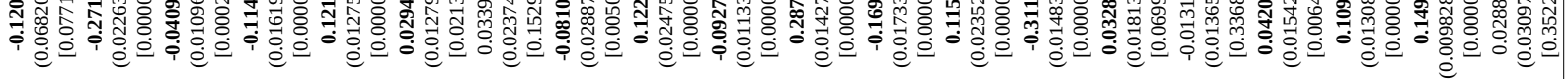

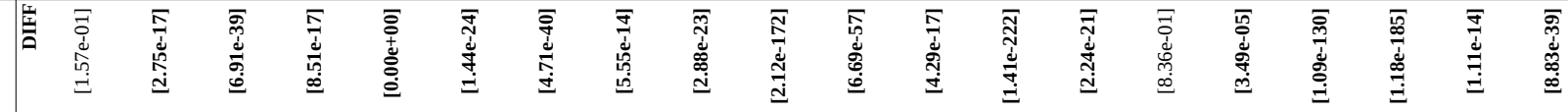

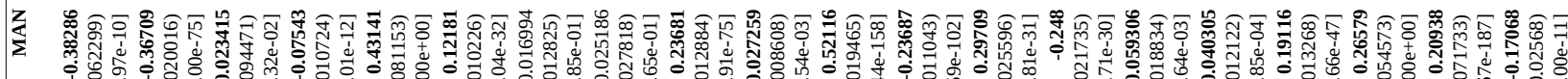

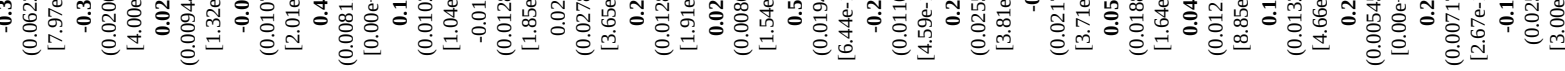

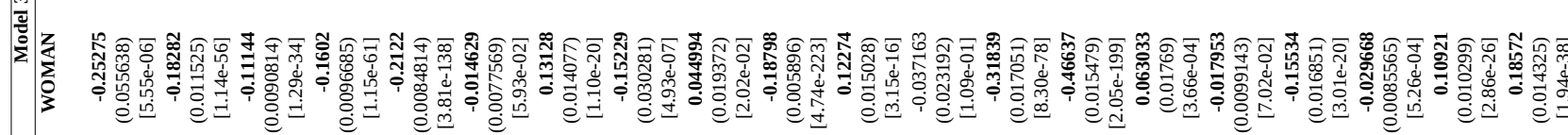

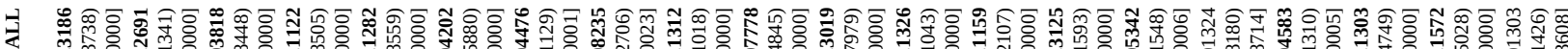

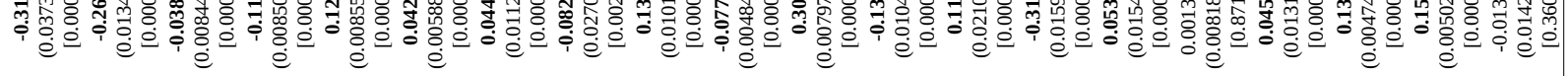

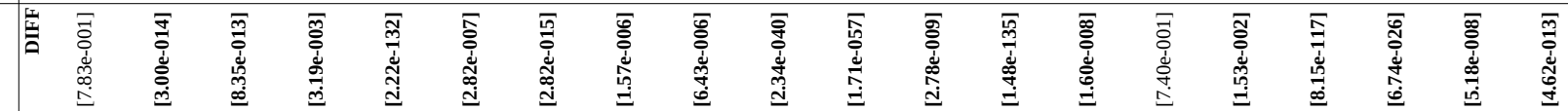

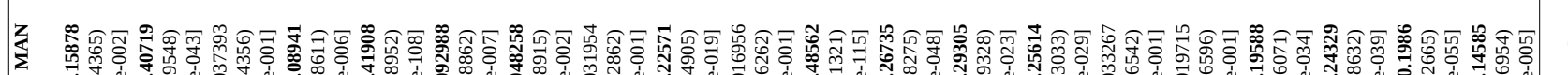

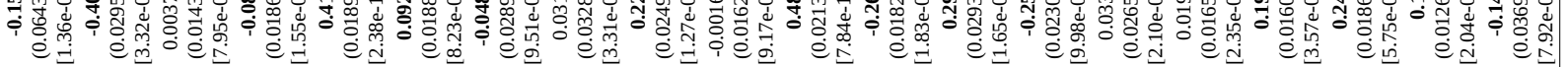

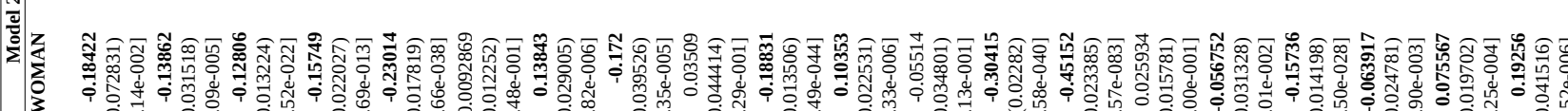

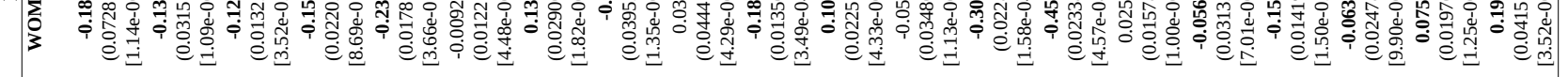

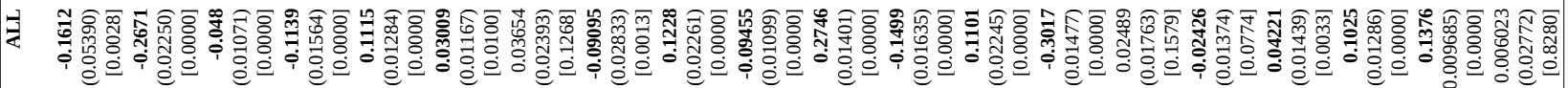

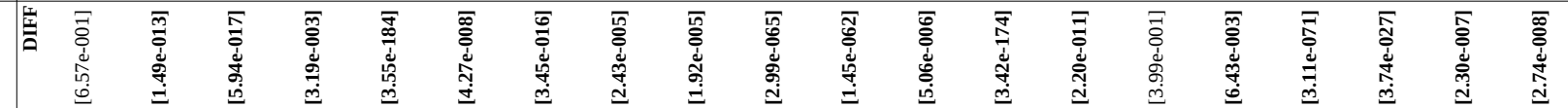

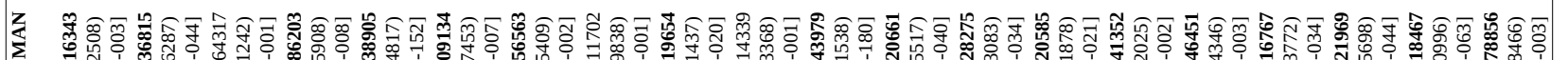

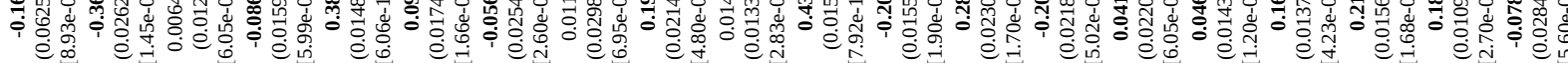

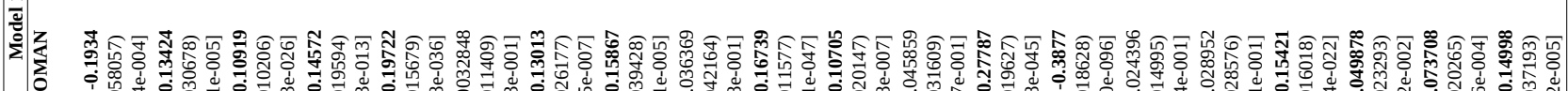

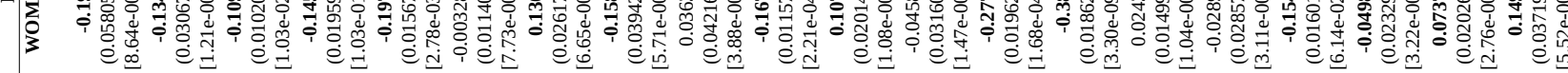

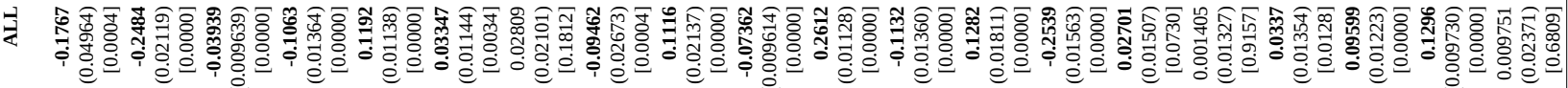

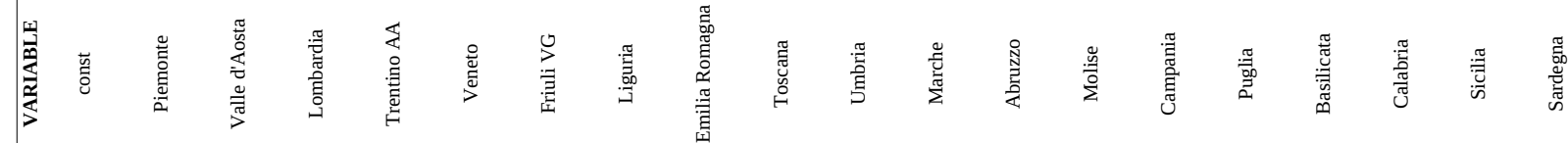


Table A2: Job and beauty dummies

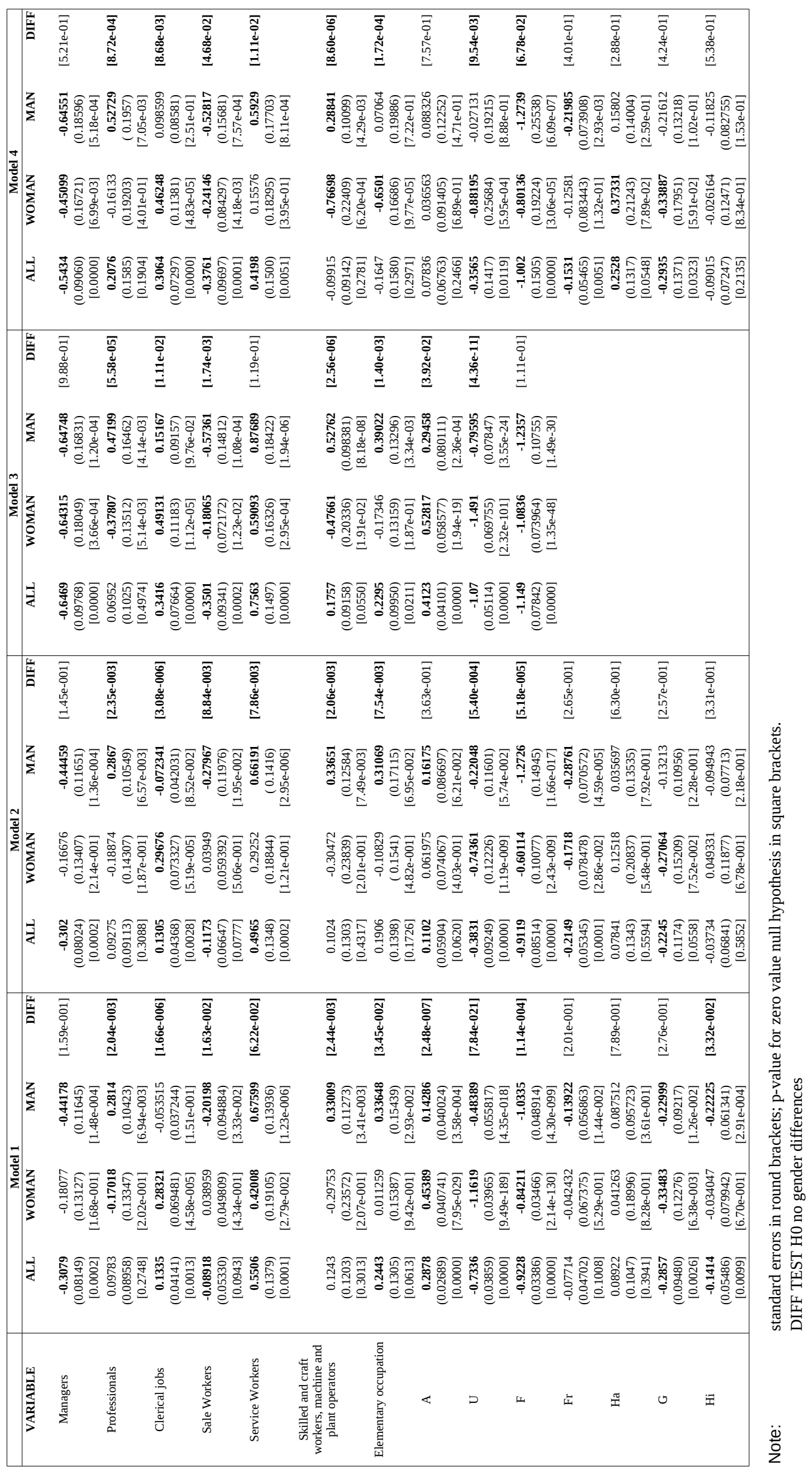


Table A3: Interactions betweeen beauty and job dummies

\begin{tabular}{|c|c|c|c|c|c|c|c|c|}
\hline \multirow[b]{2}{*}{ VARIABLE } & \multicolumn{4}{|c|}{ Model 2} & \multicolumn{4}{|c|}{ Model 4} \\
\hline & ALL & WOMAN & MAN & DIFF & ALL & WOMAN & MAN & DIFF \\
\hline \multirow[t]{3}{*}{ Fr_A } & 0.7277 & 0.66402 & 0.8156 & [1.88e-001] & 0.6388 & 0.56134 & 0.73672 & [2.01e-01] \\
\hline & (0.06533) & $(0.078615)$ & $(0.098481)$ & & (0.06697) & (0.094147) & (0.10035) & \\
\hline & {$[0.0000]$} & [3.00e-017] & [1.21e-016] & & {$[0.0000]$} & [2.49e-09] & [2.11e-13] & \\
\hline \multirow[t]{3}{*}{ Ha_A } & -1.023 & -0.83824 & -1.1815 & [4.65e-002] & -0.9221 & -0.66757 & -1.0776 & [3.31e-02] \\
\hline & (0.09386) & $(0.11546)$ & $(0.13753)$ & & $(0.07474)$ & (0.14157) & (0.11571) & \\
\hline & {$[0.0000]$} & [3.87e-013] & [8.63e-018] & & {$[0.0000]$} & [2.41e-06] & [1.24e-20] & \\
\hline \multirow[t]{3}{*}{ G_A } & 0.00428 & 0.2805 & -0.26497 & [5.21e-008] & 0.0584 & 0.27146 & -0.12836 & [6.02e-03] \\
\hline & $(0.1152)$ & (0.10555) & (0.14107) & & $(0.1004)$ & (0.089335) & $(0.15096)$ & \\
\hline & [0.9704] & [7.87e-003] & [6.03e-002] & & [0.5606] & [2.38e-03] & [3.95e-01] & \\
\hline \multirow[t]{3}{*}{ Hi_A } & 0.103 & 0.29084 & -0.078457 & [5.35e-004] & 0.1133 & 0.32021 & -0.06927 & {$[2.26 \mathrm{e}-03]$} \\
\hline & $(0.04900)$ & (0.07377) & $(0.069972)$ & & $(0.05301)$ & (0.074198) & (0.092933) & \\
\hline & [0.0355] & [8.06e-005] & [2.62e-001] & & [0.0325] & [1.59e-05] & [4.56e-01] & \\
\hline \multirow[t]{3}{*}{ Fr_U } & -0.8102 & -1.1733 & -0.64782 & [3.48e-004] & -0.9807 & -1.4791 & -0.92241 & [6.02e-02] \\
\hline & (0.07859) & $(0.12804)$ & (0.10389) & & $(0.1444)$ & $(0.34442)$ & $(0.16357)$ & \\
\hline & {$[0.0000]$} & [5.03e-020] & [4.50e-010] & & [0.0000] & [1.75e-05] & [1.71e-08] & \\
\hline \multirow[t]{3}{*}{ Ha_U } & 0.6149 & 0.63056 & 0.67225 & [7.59e-001] & 0.092 & -0.28283 & 0.3496 & [6.10e-03] \\
\hline & $(0.08757)$ & ( 0.1127) & (0.11891) & & (0.1038) & $(0.19413)$ & $(0.14204)$ & \\
\hline & {$[0.0000]$} & [2.21e-008] & [1.57e-008] & & [0.3755] & [1.45e-01] & [1.38e-02] & \\
\hline \multirow[t]{3}{*}{ G_U } & -0.2672 & -0.46126 & -0.22477 & [1.15e-001] & -0.2787 & -0.38439 & -0.31848 & [8.53e-01] \\
\hline & (0.08598) & (0.13785) & (0.10335) & & $(0.1441)$ & $(0.2964)$ & $(0.18342)$ & \\
\hline & [0.0019] & [8.20e-004] & [2.96e-002] & & [0.0532] & [1.95e-01] & [8.25e-02] & \\
\hline \multirow[t]{3}{*}{ Hi_U } & -0.7237 & -0.49129 & -0.73779 & [2.68e-001] & -0.6684 & -0.37374 & -0.80683 & [1.99e-01] \\
\hline & $(0.1073)$ & ( 0.1922) & (0.12807) & & $(0.1446)$ & $(0.26235)$ & $(0.19514)$ & \\
\hline & {$[0.0000]$} & [1.06e-002] & [8.38e-009] & & {$[0.0000]$} & [1.54e-01] & [3.56e-05] & \\
\hline \multirow[t]{3}{*}{ Fr_F } & 0.07496 & 0.09208 & -0.11131 & [1.56e-001] & -0.04888 & 0.034774 & -0.1632 & [2.43e-01] \\
\hline & $(0.08141)$ & (0.10831) & (0.11538) & & (0.07990) & ( 0.1199) & (0.13039) & \\
\hline & [0.3572] & [3.95e-001] & [3.35e-001] & & [0.5407] & [7.72e-01] & [2.11e-01] & \\
\hline \multirow[t]{3}{*}{ Ha_F } & 0.5042 & 0.23635 & 0.85341 & [9.07e-003] & 0.06771 & -0.38945 & 0.44679 & [7.46e-03] \\
\hline & (0.08388) & (0.14029) & (0.16329) & & $(0.08381)$ & $(0.14585)$ & (0.19339) & \\
\hline & {$[0.0000]$} & [9.20e-002] & [1.73e-007] & & [0.4191] & [7.58e-03] & [2.09e-02] & \\
\hline \multirow[t]{3}{*}{ G_F } & -0.24 & -0.42734 & -0.0081489 & [4.54e-002] & 0.003914 & -0.22861 & 0.32221 & [7.64e-02] \\
\hline & $(0.07431)$ & (0.11787) & ( 0.1412) & & (0.1905) & $(0.23484)$ & $(0.30426)$ & \\
\hline & [0.0012] & [2.88e-004] & [9.54e-001] & & [0.9836] & [3.30e-01] & [2.90e-01] & \\
\hline \multirow[t]{3}{*}{ Hi_F } & -0.3284 & -0.53978 & -0.13883 & [3.16e-002] & -0.2122 & -0.36731 & -0.069212 & [1.32e-01] \\
\hline & $(0.05357)$ & (0.10999) & (0.11806) & & $(0.07541)$ & $(0.13443)$ & $(0.15937)$ & \\
\hline & {$[0.0000]$} & [9.23e-007] & [2.40e-001] & & [0.0049] & [6.29e-03] & [6.64e-01] & \\
\hline
\end{tabular}

Note:

standard errors in round brackets; p-value for zero value null hypothesis in square brackets. DIFF TEST H0 no gender differences 
Table A4: Interactions betweeen beauty and job classification

\begin{tabular}{|c|c|c|c|c|c|c|c|c|}
\hline \multirow[b]{2}{*}{ VARIABLE } & \multicolumn{4}{|c|}{ Model 3} & \multicolumn{4}{|c|}{ Model 4} \\
\hline & ALL & WOMAN & MAN & DIFF & ALL & WOMAN & MAN & DIFF \\
\hline \multirow[t]{3}{*}{ Managers_A } & 0.3576 & 0.4273 & 0.28508 & [6.12e-01] & 0.6238 & 0.63908 & 0.61009 & [9.19e-01] \\
\hline & $(0.08553)$ & ( 0.195) & $(0.12677)$ & & $(0.1103)$ & $(0.18649)$ & $(0.17619)$ & \\
\hline & {$[0.0000]$} & [2.84e-02] & [2.45e-02] & & {$[0.0000]$} & [6.11e-04] & [5.35e-04] & \\
\hline \multirow[t]{3}{*}{ Professionals_A } & -0.5204 & -0.3138 & -0.68792 & [3.39e-02] & -0.3949 & -0.22605 & -0.52486 & [1.49e-01] \\
\hline & $(0.1315)$ & $(0.15034)$ & $(0.17098)$ & & $(0.1345)$ & $(0.15107)$ & $(0.19135)$ & \\
\hline & {$[0.0001]$} & [3.69e-02] & [5.74e-05] & & [0.0033] & [1.35e-01] & [6.09e-03] & \\
\hline \multirow[t]{3}{*}{ Clerical jobs_A } & 0.005302 & -0.043227 & 0.071162 & [3.60e-01] & 0.05415 & 0.0011595 & 0.15018 & [1.66e-01] \\
\hline & $(0.08596)$ & (0.093888) & $(0.11863)$ & & $(0.07780)$ & (0.095245) & (0.093853) & \\
\hline & {$[0.9508]$} & {$[6.45 \mathrm{e}-01]$} & [5.49e-01] & & {$[0.4864]$} & [9.90e-01] & [1.10e-01] & \\
\hline \multirow[t]{3}{*}{ Sale Workers_A } & 0.5979 & 0.46646 & 0.78044 & [2.30e-02] & 0.3537 & 0.3182 & 0.43122 & [3.28e-01] \\
\hline & $(0.1272)$ & $(0.10969)$ & $(0.18372)$ & & (0.1199) & $(0.11476)$ & $(0.15977)$ & \\
\hline & {$[0.0000]$} & [2.11e-05] & [2.16e-05] & & [0.0032] & [5.56e-03] & [6.95e-03] & \\
\hline \multirow[t]{3}{*}{ Service Workers_A } & -0.839 & -1.2304 & -0.55572 & [1.18e-02] & 0.07097 & -0.23894 & 0.25307 & [3.03e-02] \\
\hline & $(0.08212)$ & $(0.20284)$ & $(0.12263)$ & & (0.05549) & $(0.17003)$ & $(0.07903)$ & \\
\hline & {$[0.0000]$} & [1.31e-09] & [5.85e-06] & & [0.2009] & [1.60e-01] & [1.36e-03] & \\
\hline \multirow[t]{3}{*}{ Skilled workers_A } & -0.765 & -0.52714 & -0.84324 & [7.94e-02] & -0.1381 & 0.036434 & -0.1955 & [1.97e-01] \\
\hline & $(0.08909)$ & $(0.10671)$ & $(0.1357)$ & & $(0.08467)$ & $(0.14728)$ & $(0.1076)$ & \\
\hline & {$[0.0000]$} & [7.81e-07] & [5.17e-10] & & [0.1029] & [8.05e-01] & [6.92e-02] & \\
\hline \multirow[t]{3}{*}{ Elementary occupation_A } & -1.297 & -1.8286 & -1.1417 & [5.27e-02] & -0.274 & -0.86171 & -0.12269 & [1.09e-01] \\
\hline & $(0.1353)$ & $(0.34472)$ & $(0.15759)$ & & $(0.1204)$ & $(0.42066)$ & $(0.13886)$ & \\
\hline & {$[0.0000]$} & [1.13e-07] & [4.32e-13] & & [0.0229] & [4.05e-02] & [3.77e-01] & \\
\hline \multirow[t]{3}{*}{ Managers_U } & 0.4221 & & 0.51525 & & -0.007355 & & 0.069637 & \\
\hline & $(0.1318)$ & & $(0.078493)$ & & $(0.1193)$ & & $(0.067869)$ & \\
\hline & {$[0.0014]$} & & {$[5.23 \mathrm{e}-11]$} & & [0.9509] & & [3.05e-01] & \\
\hline \multirow[t]{3}{*}{ Professionals_U } & 0.4858 & 0.57237 & 0.25991 & {$[4.20 \mathrm{e}-02]$} & 0.1781 & 0.45076 & -0.047575 & [2.34e-02] \\
\hline & $(0.09827)$ & $(0.17534)$ & $(0.12974)$ & & $(0.1174)$ & $(0.24774)$ & $(0.11526)$ & \\
\hline & {$[0.0000]$} & [1.10e-03] & {$[4.51 \mathrm{e}-02]$} & & [0.1292] & [6.88e-02] & [6.80e-01] & \\
\hline Clerical jobs_U & -0.6735 & -0.5173 & -0.65225 & [4.94e-01] & -0.9611 & -0.73669 & -0.9817 & [3.38e-01] \\
\hline & $(0.09784)$ & $(0.14398)$ & $(0.1411)$ & & $(0.1006)$ & $(0.14485)$ & $(0.17742)$ & \\
\hline & {$[0.0000]$} & [3.27e-04] & [3.79e-06] & & {$[0.0000]$} & [3.66e-07] & [3.15e-08] & \\
\hline Sale Workers_U & 0.03776 & -0.051608 & 0.21953 & [8.82e-02] & 0.4897 & 1.0055 & 0.55835 & [7.69e-02] \\
\hline & $(0.1226)$ & $(0.16538)$ & $(0.1242)$ & & $(0.2268)$ & $(0.36162)$ & $(0.24727)$ & \\
\hline & {$[0.7581]$} & [7.55e-01] & [7.71e-02] & & [0.0308] & [5.43e-03] & [2.39e-02] & \\
\hline Service Workers_U & 1.05 & 1.3055 & 0.90284 & [2.01e-03] & 0.3389 & 0.95115 & 0.046319 & [2.08e-03] \\
\hline & $(0.08848)$ & $(0.11581)$ & $(0.111)$ & & (0.1199) & $(0.2161)$ & $(0.19003)$ & \\
\hline & {$[0.0000]$} & [1.78e-29] & [4.17e-16] & & [0.0047] & [1.08e-05] & [8.07e-01] & \\
\hline Skilled workers_U & 0.9287 & 1.2559 & 0.66618 & [2.64e-03] & 0.47 & 1.0444 & 0.029946 & [1.68e-04] \\
\hline & $(0.1016)$ & $(0.14778)$ & $(0.13874)$ & & $(0.1003)$ & $(0.21208)$ & $(0.12573)$ & \\
\hline & {$[0.0000]$} & [1.91e-17] & [1.57e-06] & & {$[0.0000]$} & [8.45e-07] & [8.12e-01] & \\
\hline Elementary occupation_U & 1.353 & 1.5463 & 1.1939 & [1.02e-02] & 0.7567 & 1.4462 & 0.30771 & [9.79e-04] \\
\hline & $(0.09523)$ & $(0.081917)$ & $(0.13037)$ & & (0.1988) & $(0.2755)$ & $(0.2708)$ & \\
\hline & {$[0.0000]$} & [1.78e-79] & [5.29e-20] & & {$[0.0001]$} & [1.53e-07] & [2.56e-01] & \\
\hline Managers_F & -0.05003 & 0.18883 & & & -0.2009 & 0.13569 & & \\
\hline & $(0.3191)$ & $(0.29413)$ & & & $(0.3365)$ & $(0.32644)$ & & \\
\hline & [0.8754] & [5.21e-01] & & & [0.5506] & [6.78e-01] & & \\
\hline Professionals_F & -0.1011 & 0.16423 & -0.32929 & [5.18e-02] & -0.2474 & 0.10404 & -0.60057 & [4.94e-03] \\
\hline & $(0.09827)$ & $(0.16043)$ & $(0.16057)$ & & $(0.2011)$ & $(0.21952)$ & $(0.25816)$ & \\
\hline & {$[0.3035]$} & [3.06e-01] & [4.03e-02] & & {$[0.2186]$} & [6.36e-01] & [2.00e-02] & \\
\hline Clerical jobs_F & -0.4179 & -0.36689 & -0.88535 & [5.15e-02] & -0.4391 & -0.41805 & -0.88624 & [8.12e-02] \\
\hline & $(0.1352)$ & $(0.15834)$ & ( 0.2359) & & $(0.1442)$ & $(0.1706)$ & $(0.23199)$ & \\
\hline & {$[0.0020]$} & [2.05e-02] & [1.75e-04] & & [0.0023] & [1.43e-02] & [1.33e-04] & \\
\hline Sale Workers_F & 0.4977 & 0.60112 & -0.085044 & [1.22e-04] & 0.4666 & 0.50254 & -0.04686 & [1.92e-02] \\
\hline & (0.1029) & $(0.11256)$ & $(0.13062)$ & & $(0.1318)$ & $(0.15327)$ & $(0.19753)$ & \\
\hline & {$[0.0000]$} & [9.28e-08] & [5.15e-01] & & {$[0.0004]$} & [1.04e-03] & [8.12e-01] & \\
\hline Service Workers_F & 0.1093 & 0.10955 & 0.13021 & {$[9.52 \mathrm{e}-01]$} & -0.0851 & 0.15737 & -0.098416 & [3.93e-01] \\
\hline & $(0.1172)$ & $(0.23049)$ & $(0.18334)$ & & $(0.1419)$ & $(0.22605)$ & $(0.21986)$ & \\
\hline & {$[0.3511]$} & [6.35e-01] & {$[4.78 \mathrm{e}-01]$} & & [0.5485] & [4.86e-01] & {$[6.54 \mathrm{e}-01]$} & \\
\hline Skilled workers_F & 0.705 & 1.0854 & 0.54838 & [6.87e-04] & 0.5685 & 1.088 & 0.34839 & [5.06e-03] \\
\hline & $(0.1537)$ & $(0.13406)$ & $(0.20102)$ & & $(0.2313)$ & $(0.16255)$ & $(0.34875)$ & \\
\hline & {$[0.0000]$} & [5.69e-16] & [6.37e-03] & & {$[0.0140]$} & [2.18e-11] & [3.18e-01] & \\
\hline Elementary occupation_F & 1.164 & 1.4524 & 1.1102 & [5.19e-02] & 0.9639 & 1.5408 & 0.76223 & [8.61e-04] \\
\hline & $(0.09725)$ & $(0.14229)$ & $(0.12914)$ & & $(0.1736)$ & $(0.21948)$ & $(0.24658)$ & \\
\hline & {$[0.0000]$} & [1.84e-24] & [8.22e-18] & & {$[0.0000]$} & [2.22e-12] & [1.99e-03] & \\
\hline
\end{tabular}

Note:

standard errors in round brackets; p-value for zero value null hypothesis in square brackets.

DIFF TEST H0 no gender differences 
Table A5: TESTS

\begin{tabular}{|c|c|c|c|c|c|c|c|c|}
\hline \multirow[b]{2}{*}{ VARIABLE } & \multicolumn{2}{|r|}{ Model 1} & \multicolumn{2}{|r|}{ Model 2} & \multicolumn{2}{|r|}{ Model 3} & \multicolumn{2}{|r|}{ Model 4} \\
\hline & ALL & GENDERIFIED & ALL & GENDERIFIED & ALL & GENDERIFIED & ALL & GENDERIFIED \\
\hline n obs. & 11008 & 11008 & 11008 & 11008 & 11008 & 10872 & 11008 & 10872 \\
\hline Dependent Mean & 0.298 & 0,298 & 0,298 & 0,298 & 0,298 & 0,302 & 0,298 & 0,302 \\
\hline McFadden's R ${ }^{2}$ & 0.132 & 0.163 & 0.207 & 0.237 & 0.194 & 0.218 & 0.222 & 0.249 \\
\hline $\ln L$ & -5816 & -5610 & -5318 & -5117 & -5402 & -5208 & -5216 & -4999 \\
\hline Schwarz's criterion & 11949 & 11852 & 11065 & 11090 & 11279 & 11345 & 11055 & 11224 \\
\hline Akaike's criterion & 11701 & 11355 & 10729 & 10417 & 10906 & 10615 & 10565 & 10261 \\
\hline Normality (p value) & 0,000 & 0,000 & 0,006 & 0,049 & 0,666 & 0,414 & 0,000 & 0,001 \\
\hline Correct predictions & $70.2 \%$ & $72.8 \%$ & $75.2 \%$ & $76.3 \%$ & $74.6 \%$ & $75.5 \%$ & $76.2 \%$ & $76.9 \%$ \\
\hline$\%$ of true 0 & $89.9 \%$ & $88.7 \%$ & $88.7 \%$ & $89.4 \%$ & $87.3 \%$ & $86.1 \%$ & $89.3 \%$ & $87.7 \%$ \\
\hline$\%$ of true 1 & $23.6 \%$ & $35.3 \%$ & $43.4 \%$ & $45.6 \%$ & $44.6 \%$ & $50.8 \%$ & $45.5 \%$ & $51.7 \%$ \\
\hline
\end{tabular}

